\title{
LA CALIDAD DE LA DENSIDAD URBANA EN BOGOTÁ
}

Óscar A. Alfonso Roa*

$\mathrm{L}$ a medida usual de la distribución de la población es su densidad; una medida de su calidad capta elementos socio-geográficos que aquella no considera (p. ej., la proximidad a espacios libres y a equipamiento público o la mezcla social) y ayuda a entender la estructura residencial de las metrópolis latinoamericanas, una de cuyas características es la segregación socio-espacial. En Bogotá las densidades más altas suelen ser las de peor calidad dada su urbanización incompleta. La división de Bogotá en Unidades de Planeamiento Zonal (UPZ) establecida a comienzos de siglo facilita el análisis de la densidad bruta y de su calidad. En la primera sección de este artículo se repasan los enfoques teóricos y se propone una medida de la calidad. La segunda sección expone el método para hacer esa medición y construir un índice de calidad de la densidad (ICD); la tercera analiza la densidad bruta y su calidad en las UPZ. Las reflexiones finales resaltan el papel de la política y la regulación urbanas en el combate a la segregación.

\section{TEORÍAS DE LA DENSIDAD URBANA}

Los enfoques dominantes en el estudio de la densidad presuponen que los gradientes de densidad tienden a acotarse en las urbes en crecimiento, lo que era válido en América Latina a mediados del siglo pasado. La intensa urbanización periférica modificó esa tendencia e

\footnotetext{
* Doctor en Planeación Urbana, profesor e investigador del grupo Construcción de Estado, Territorio y Paz de la Universidad Externado de Colombia, Bogotá, Colombia, [oscar.alfonso@uexternado.edu.co]. Agradezco a Laura L. Amézquita su apoyo en la elaboración de este trabajo. Fecha de recepción: 21 de enero de 2016, fecha de modificación: 16 de marzo de 2016, fecha de aceptación: 12 de mayo de 2016. Sugerencia de citación: Alfonso R., Ó. "La calidad de la densidad urbana en Bogotá", Revista de Economía Institucional 18, 34, 2016, pp. 229-253. DOI: http://dx.doi.org/10.18601/01245996.v18n34.13
} 
hizo más difícil el análisis de la estructura residencial. Otros enfoques argumentan que se prefiere habitar en zonas con mayor infraestructura de transporte, propicias para la especulación inmobiliaria y que, por ello, los cambios de uso del suelo hacia actividades más rentables son más frecuentes en áreas mejor dotadas de capital fijo urbano. El papel de la política y la regulación urbanas en las pautas de ocupación poco se ha considerado, igual que la segmentación que provoca el mercado inmobiliario en contextos de profunda desigualdad social.

\section{ESTUDIOS SOBRE LAS CIUDADES DE PAÍSES CENTRALES}

Fouchier (1994) analizó los efectos sociales del incremento de la intensidad de contactos debido al aumento de la densidad; más tarde argumentó que la densidad es modulada por la presencia de diversas categorías sociales y encontró que la regulación urbana crea mecanismos jurídicos que pueden modular la intensidad de uso del suelo (Fouchier, 1997, citado por Le Roux, 2015, 31). Acioly y Forbes (1998) plantearon que la densidad afecta la convivencia y la diversidad. Para esos autores la densidad es un resultado histórico en el que se imbrican diversas etapas de desarrollo urbano, difícil de reducir a una constante espacio-temporal.

Los teóricos ortodoxos recurren al modelo de ciudad central que gravita sobre un distrito central de negocios (DCN) para explicar un gradiente de densidad que se acota con el paso del tiempo, sobre el que operan fuerzas de mercado que representan como subastas de rentas del suelo (Fujita, 1989,11-42) en las que las mayores rentas del suelo racionan el uso del suelo en el DCN promoviendo desarrollos con menor área residencial privada que en otros lugares. Las "buenas" densidades corresponden a mejores dotaciones de infraestructura pública (ibíd., 202). Wingo (1972, 96 y ss.) supuso una sociedad irreal homogénea en gustos e ingresos, pero Fujita criticó esa idea y demostró que es posible un equilibro espacial así diferentes "tipos" de familias concurran a la subasta.

Merlin (1994) compara la densidad resultante de viviendas unifamiliares y vehículo particular en países capitalistas con la de países ex comunistas inclinados a edificios colectivos y transporte masivo. Esas preferencias implican maneras distintas de distribuir la población y suscitan debates sobre la eficiencia de cada tipo de organización social, en especial sobre el uso del suelo. Algunos de estos debates giraron en torno a las ciudades monocéntricas, donde hay una estrecha relación entre infraestructura de transporte, precios del suelo e intensidad de uso (Wingo, 1972). 
Clark y Moir (2015) mencionan las características para calificar de "buena" o "mala" a una densidad", según las cuales se consideró que, en Europa, Londres (38\%), París (13\%) y Barcelona (9\%) son las ciudades con mejor densidad; y en el resto del mundo, Singapur (31\%), Nueva York (20\%) y Hong Kong (11\%). Ese trabajo muestra que aún se desconoce la potencialidad de la densificación pese a que en 2050 dos tercios de la humanidad vivirán en ciudades.

\section{ENFOQUES LATINOAMERICANOS}

Según Mohan (1975), la distribución de la población en ciudades del Tercer Mundo sigue un patrón tipo $y=a x^{-b}$, donde $y$ es el precio del suelo, $x$ la distancia al centro, y $a$ y $b$ constantes. Rakesh comparó el patrón de Bogotá, Lima y Santiago de Chile con el de Kinshasa, Hong Kong, Singapur y varias ciudades de India, y encontró que Bogotá tuvo las mayores tasas de crecimiento poblacional en las dos décadas anteriores a su estudio. E1 gradiente de densidades $b$ guardaba relación directa con el de precios del suelo y tendía a acotarse con el paso del tiempo. En su estudio sobre Bogotá, Amato (1969, citado por Le Roux, 2015, 130) observó que los hogares más pobres tendían a agruparse en zonas alejadas del centro donde se presumía que aumentaría la densidad y se fragmentaría el gradiente $b^{2}$, de modo que las zonas con mayor densidad bruta no tienen los precios del suelo más altos.

Según Jaramillo (2009), la formación de rentas precede a la edificación; por ello, los precios del suelo son mayores donde su uso es más intenso, como en la construcción en altura. Abramo (2011a) critica la visión ahistórica de la sustitución de la tierra por otros factores y plantea que la densidad obedece a estrategias de anticipación del futuro de la ciudad de los agentes inmobiliarios cuyas innovaciones generan incertidumbre urbana.

En su estudio de la urbanización popular en México, Eibenschutz y Benlliure $(2009,191)$ encontraron que los precios del suelo aumentan en cada etapa de asentamiento: ocupación, regularización de la propiedad, aumento de las dotaciones públicas y consolidación. La intervención reactiva del Estado tarda cada vez menos: los asen-

\footnotetext{
${ }^{1}$ En la "buena" densidad hay uso mixto del suelo, es conectada, planeada a ritmo incremental, cohesiva, vivible, espaciosa, el nivel de vida es similar, hay buen diseño y un medio ambiente amigable y adecuado. La "mala" densidad es monótona, aislada, crece a ritmo inmanejable, hay segregación, es invivible, hacinada e inflexible; además, hay mal diseño, contaminación y un paisaje urbano feo e inapropiado (p. 11).

${ }^{2}$ Es decir, dejaría de seguir la tendencia prevista.
} 
tamientos surgidos a mediados del siglo pasado se regularizaron a finales de siglo; a los que surgieron a finales de siglo les tomó una década el inicio de la regularización.

Alfonso (2007) atribuye una parte de los cambios de densidad a la reducción del tamaño del hogar debida al aumento de hogares unipersonales. Y otra parte a la competencia por localización residencial entre hogares adinerados y al papel de las principales jurisdicciones que proveen suelo habitable a hogares de ingresos muy bajos.

Las dinámicas que dificultan una lectura exacta del orden urbano latinoamericano son características de un nuevo tipo de poblamiento a escalas temporales y espaciales diferenciadas. La base de esta tesis de Le Roux $(2015,5)$ es que la desigual densidad de población refleja la desigualdad entre grupos sociales, y que depende del contexto, pues en las urbes de los países centrales no se observa una relación lineal entre mezcla social y alta densidad. A finales de los sesenta, la población más rica de Bogotá residía en zonas de baja densidad, las capas medias en zonas de alta densidad y las pobres en zonas de densidad media (ibíd., 31). La densificación posterior a los noventa se concentra en la periferia, en especial en antiguos barrios de origen informal, por la producción residencial en serie alejada del centro (ibíd., 151), pero no se observa una relación lineal entre mezcla social y densidad.

\section{CALIDAD Y PROXIMIDAD GEOGRÁFICA}

La calidad de la densidad urbana refleja los avances o retrocesos de la segregación residencial que exigen renovar el estudio de las urbes latinoamericanas. Hoy las proximidades organizadas o relacionales entre individuos son decisivas en la estructuración social y la proximidad geográfica en la estructuración socio-espacial: "la proximidad ofrece un recurso, el contacto directo y permanente con otros individuos, organizaciones o instituciones" (Rallet, 2002, 59).

La medida de la calidad que aquí se propone parte de observar que se prefieren bajas densidades, y esto sugiere que existe un primer mecanismo de segregación socio-espacial: los hogares inclinados a segregarse pagan más por vivir en las zonas menos densas. Los gradientes de densidad toman valores diferentes según la orientación espacial del esquema de segregación, porque las zonas populares muy densas están más alejadas de las zonas nobles que los vecindarios de las capas medias-altas o medias. Esos gradientes no convergen en el tiempo sino que divergen debido a la concentración del ingreso y al carácter reactivo de la intervención estatal. 
La calidad de la densidad es localizada; por ello la proximidad geográfica entre personas es decisiva, pues a diferencia de otro tipo de proximidades no espaciales cualifica un vecindario. La existencia de dotaciones de bienes públicos próximos hace más fácil que los residentes de ciertas zonas superen dificultades específicas e influye en su decisión de localización. La existencia de bienes club y el acceso a servicios privados de salud, educación, cultura y culto contrasta con el carácter público de esos bienes en las zonas populares, donde además se concentran otros equipamientos de bienestar social: comedores comunitarios o ancianatos. Y se evita la existencia de cárceles, leprocomios, depósitos de combustibles y cementerios debido a sus externalidades negativas; el síndrome del "nimbismo" explica el rechazo a construir este tipo de bienes y la demanda de compensaciones por la pérdida de calidad de vida (Wolsink, 2000, 50).

El paisaje urbano consiste en construcciones de cemento, acero y asfalto que aglomeran actividades humanas en espacios que propician contactos efímeros y provocan estrés. Por ello, hay una demanda creciente de espacios libres próximos, donde además de esparcimiento y cambio de paisaje se produzcan interacciones menos fugaces que los encuentros anónimos rutinarios. Muchos residentes no satisfacen esa demanda in situ y se deben desplazar a otros lugares o postergar el uso del espacio público hasta el fin de semana.

La dimensión espacial de la interacción entre personas es central en los trabajos sobre proximidad (Rallet, 2002, 65). Los enfoques según los cuales las capas sociales están formadas por individuos con semejanzas económicas, raciales o idiosincrásicas explican el conservadurismo de los agentes de segregación residencial; otros enfoques que promueven la mezcla social denuncian el "clasismo". El tipo ideal de mezcla social satisfaría el deseo de los trabajadores de una mejor localización que aumente su productividad y mejore su calidad de vida. La mezcla social propicia interacciones que aumentan la confianza y, con ella, mejoras en la "equidad entre personas" y en la "prosperidad de los lugares" (Richardson, 1986, 169).

Los barrios exclusivos resaltan la precariedad de los demás barrios de la ciudad. La cercanía entre las casonas de los terratenientes y la vivienda de los capataces, y entre esta y las casuchas de los trabajadores, obedecía a que unos y otros dudaban de su buena fe. La cercanía facilita la vigilancia. En las urbes actuales la segregación socio-espacial se suele justificar en aras de la seguridad del vecindario, que excluye familias de "clase inferior". Aparecen entonces el monoclasismo y su 
ethos diferenciador: competencia y aislamiento en los barrios exclusivos; solidaridad y bullicio en los barrios populares.

La densidad de ocupación y su calidad reflejan la segregación residencial causada por la gestión de la ocupación del territorio: las densidades brutas más bajas son las de mejor calidad, en vecindarios de familias pudientes; las de peor calidad se observan en zonas populares. No hay una explicación única para este hecho, pero entre las principales cabe mencionar que la alta capacidad de las familias adineradas para pagar la localización genera exclusividad residencial y que las mejoras de la calidad urbanística son inducidas por la búsqueda de economías de escala en los vecindarios populares más densos, donde el Estado ejecuta sus políticas reactivas.

Esa situación se representa en la gráfica 1: la mejor calidad de la densidad (CD) se encuentra en barrios exclusivos $\left(\mathrm{D}_{1}\right)$, de residencias construidas por encargo de sus propietarios, invadidos por conjuntos cerrados y edificios de apartamentos que aumentan sutilmente la densidad bruta (DB), de por sí muy baja, pero mantienen la exclusividad mediante instrumentos de mercado, como la calidad de la vivienda y sus áreas privadas, dotaciones complementarias, número de garajes y precio de las viviendas; y de regulaciones como la clasificación del suelo, las normas de uso y las licencias urbanísticas y de construcción. Las economías de vecindad son las más altas y por ello las más apetecidas, pero esos instrumentos bloquean la entrada de vecinos indeseados.

Por debajo de $\mathrm{D}_{1}$ se sitúan vecindarios con un mejor uso del suelo para fines residenciales que se refleja en el aumento de la densidad bruta $\left(D_{2}\right.$ a $\left.D_{4}\right)$, aunque se reduce la calidad de la densidad. La escasez de espacios libres y la congestión debida a la mayor demanda de bienes públicos no son compensadas por la mejora de las mezclas sociales de orden intermedio. Las convenciones urbanas son frágiles y por ello algunos vecindarios son más propensos que otros a los vaivenes del mercado inmobiliario y a su eslabón financiero, el mercado hipotecario. Los vecindarios de tipo $\mathrm{D}_{4}$ cumplen dos funciones cruciales en las urbes latinoamericanas: establecen el límite inferior de calidad de la densidad $\left(\mathrm{U}_{\mathrm{CD}}\right)$ producida formalmente y la frontera de densidad bruta $\left(\mathrm{U}_{\mathrm{DB}}\right)$ permisible por la regulación urbana.

Por debajo de $\mathrm{U}_{\mathrm{CD}}$ se sitúan los barrios de origen informal, al menos la mitad de las zonas de residencia en América Latina. En $U_{D B}$ hay una fractura, que representa la intervención estatal reactiva. Los vecindarios $\mathrm{D}_{5}$ han sido objeto de programas de regularización de la propiedad y de mejoramiento urbano que mejoran los equipamientos 
Gráfica 1

Densidad bruta y su calidad en las metrópolis latinoamericanas

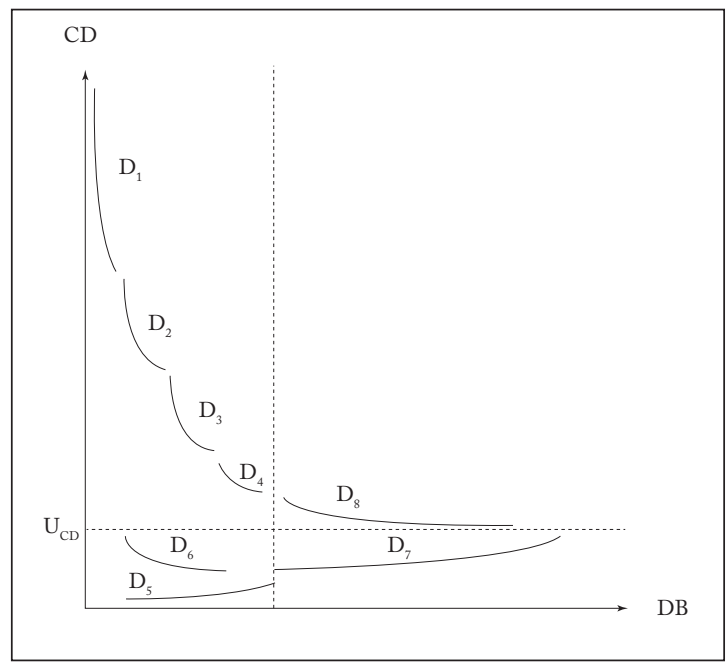

Fuente: elaboración del autor.

y las dotaciones de uso público, y subsanan la precariedad de capital fijo urbano; los $\mathrm{D}_{7}$ esperan tal intervención. Las mejoras de dotación e infraestructura no permiten superar el umbral de calidad de la densidad porque la mezcla social es casi inexistente o es tan baja que tiende al monoclasismo. Este tipo de vecindarios se sitúa más allá de $\mathrm{U}_{\mathrm{DB}}$, lo que denota el carácter reactivo de la intervención estatal, es decir, que el Estado actúa cuando la densidad bruta supera los límites establecidos para contener el desorden urbano. Los vecindarios de tipo $D_{7}$ están en una fase anterior a la de los de tipo $D_{5}$ y reflejan ese desorden, pues comienzan con bajas densidades brutas, como las de los vecindarios $\mathrm{D}_{1}$ a $\mathrm{D}_{4}$, pero con una calidad irrisoria.

Los vecindarios de tipo $\mathrm{D}_{6}$ han sido poco estudiados. Se ubican cerca de zonas industriales que generan externalidades negativas y riesgos latentes para sus residentes. La productividad aparente de los trabajadores fabriles in situ es superior a la del conjunto, pero no implica una mejor calidad de vida de sus hogares porque el salario no refleja sus aportes a la producción. Habitan allí por estabilidad laboral o porque el desempleo friccional es menor que en el conjunto de la ciudad. La pendiente negativa de los barrios $\mathrm{D}_{6}$ los diferencia de los $\mathrm{D}_{5}$ porque no son objeto de intervención urbanística estatal, y el aumento de la densidad bruta se relaciona negativamente con su calidad.

La construcción de viviendas para familias de ingreso medio-bajo mejora la mezcla social en barrios de tipo $\mathrm{D}_{8}$, donde la urbanización 
por autoconstrucción contrasta con la monótona silueta de la urbanización formal en serie. La densidad bruta aumenta pero la mejora de su calidad es casi marginal. La abrupta redensificación de estos vecindarios lleva al colapso de la movilidad cotidiana, con sus efectos sobre la productividad laboral.

\section{MEDICIÓN DE LA CALIDAD}

La unidad de observación es la UPZ, para la que se acopiaron estadísticas sobre los cuatro componentes del ICD, según sus características predominantes. Todas las variables $x_{i}$ se pueden estandarizar captando las distancias en índices sintéticos y agrupando los componentes del ICD de modo que reflejen su independencia y su insustituibilidad.

$$
X_{i}=\frac{X_{\text {observado }}-X_{\text {minimo }}}{X_{\text {maximo }}-X_{\text {minimo }}}
$$

Los valores mínimos y máximos pueden resultar de un tipo ideal que exprese las aspiraciones colectivas y una norma social adecuada a cierta visión de la sociedad, o derivarse de un ejercicio de parametrización. No obstante las ventajas y desventajas de estos procedimientos, aquí se emplean los valores observados para evitar discusiones sobre cifras de densidad óptima.

La densidad bruta es el cociente entre la población de la UPZ y su área urbana. El deseo de bajas densidades se expresa en un índice del inverso de la densidad bruta $\left(\mathrm{I}_{\mathrm{D}}\right)$; así, el deseo de las densidades más bajas se acerca a 1 y el de las más altas a 0 . La dotación de bienes públicos se capta en un índice $\left(\mathrm{I}_{\mathrm{p}}\right)$ que cubre bienes y activos culturales, edificaciones para culto, equipamientos para atención al ciudadano y bienestar social, hospitales y colegios públicos y privados. Para los espacios libres cercanos el índice $\left(\mathrm{I}_{\mathrm{E}}\right)$ capta la existencia de espacios deportivos y recreativos, la extensión de parques metropolitanos y de parques barriales. Como proxy del índice de mezcla social $\left(\mathrm{I}_{\mathrm{M}}\right)$ se usa la estratificación socioeconómica, elaborada a comienzos de los ochenta para subsidiar los servicios públicos domiciliarios y que hoy refleja las diferencias sociales e incide en el precio de la vivienda, los impuestos a la propiedad y la segregación socio-espacial (Uribe, 2008, 143). En este análisis se emplea como proxy de la capacidad de pago y se aprovecha su actualización reciente para establecer las diferencias con una mezcla social con características de un tipo ideal de 3,5, intermedia entre el estrato medio-bajo (3) y el estrato medio (4), que supone un número igual de residentes de los seis estratos en cada UPZ. Por encima de ese valor es una mezcla social virtuosa y por 
debajo una mezcla indeseable. $\mathrm{E} 1$ valor de $\mathrm{I}_{\mathrm{M}}$ oscila entre 1 y 0 . Los índices estandarizados captan las distancias entre las variables respectivas. Cuando se promedian, esos índices dan la misma ponderación a fenómenos no sustituibles per se.

$I C D=\frac{I_{D}+I_{P}+I_{E}+I_{M}}{4}$

El ICD se basa en el hecho de que el espacio geográfico y sus dominios determinan la calidad de vida; por ello la política urbana del Estado no puede relegarse a un segundo plano, a la espera de que las políticas de redistribución del ingreso y la riqueza mejoren la capacidad de pago de los pobres para vivir en mejores vecindarios y se reduzca la segregación residencial (Alfonso y Alonso, 2015). El apartado siguiente analiza la densidad y su calidad a la luz de la clasificación del suelo urbano.

\section{REGULACIÓN, CALIDAD DE LA DENSIDAD Y SEGREGACIÓN}

De los tres modos posibles de satisfacer la demanda de espacio habitable causada por el crecimiento de la población -formación de nuevas ciudades, expansión de las existentes y densificación-, en Colombia se ha optado por los dos últimos. La densificación es el más empleado en Bogotá (cuadro 1).

Cuadro 1

Densidad de población promedio, 1900-2015

\begin{tabular}{lccc}
\hline Año & Población & $\begin{array}{c}\text { Área } \\
\text { (ha) }\end{array}$ & $\begin{array}{c}\text { Densidad } \\
\text { (habitantes } / \mathrm{km}^{2} \text { ) }\end{array}$ \\
\hline 1900 & 96.605 & 260 & 37.156 \\
1910 & 116.750 & 538 & 21.701 \\
1985 & 4.351 .240 & 37.998 & 11.102 \\
2015 & 7.862 .277 & 37.998 & 20.691 \\
\hline
\end{tabular}

Fuente: Alfonso (2012) y proyecciones de población del DANE.

La regulación urbana incide en la densidad a través de la clasificación de usos del suelo. En 1990 la Alcaldía adoptó tres niveles de zonificación y previó la regulación de áreas de actividad múltiple y de actividad especializada. En 2000 se aprobó un nuevo plan de ordenamiento territorial que delimitó 108 UPZ o "unidades territoriales conformadas por un barrio o conjunto de barrios tanto en suelo urbano como en suelo de expansión, que mantienen unidad morfológica o funcional" (art. 447, Decreto 619 de 2000) para establecer los requerimientos de equipamientos, vías y espacio público. En el documento técnico de soporte se establecieron ocho tipos: 
1. Residencial de urbanización incompleta: periferia sin consolidar habitada por familias pobres, de uso residencial predominante con acceso, equipamientos, espacio y bienes públicos deficientes.

2. Residencial consolidado: zonas consolidadas habitadas por familias de estrato medio, de uso residencial predominantemente, con potencial de cambio de uso y aumento descontrolado de la ocupación.

3. Residencial cualificado: zonas consolidadas habitadas por familias de estrato medio y alto, de uso residencial, con las mejores dotaciones públicas de la ciudad.

4. Desarrollo: zonas poco desarrolladas, con vacíos urbanos.

5. Con centralidad urbana: zonas consolidadas donde el uso residencial dominante ha sido desplazado por otros usos, con aglomeración de otras actividades económicas.

6. De predominio comercial: zonas destinadas al intercambio de bienes y servicios.

7. De predomínio industrial: zonas para uso industrial y atividades complementarias.

8. De predominio dotacional: zonas para equipamientos urbanos que requieren tratamiento especial.

Cuadro 2

Densidad bruta por características predominantes de las UPZ, 2014

\begin{tabular}{|c|c|c|c|c|c|}
\hline \multirow{2}{*}{$\begin{array}{l}\text { UPZ } \\
\text { Clasificación del suelo }\end{array}$} & \multirow[b]{2}{*}{$\begin{array}{c}\text { Número de } \\
\text { zonas }\end{array}$} & \multicolumn{2}{|c|}{ Población } & \multicolumn{2}{|c|}{$\begin{array}{l}\text { Densidad bruta } \\
\text { (Personas/ha) }\end{array}$} \\
\hline & & Habitantes & $\begin{array}{c}\text { Participación } \\
(\%)\end{array}$ & Máxima & Mínima \\
\hline Residencial, urbanización incompleta & 32 & 3.439 .677 & 44,4 & 622 & 124 \\
\hline Residencial consolidado & 29 & 2.540 .481 & 32,8 & 466 & 132 \\
\hline Residencial cualificado & 11 & 520.411 & 6,7 & 200 & 78 \\
\hline Desarrollo & 9 & 228.421 & 2,9 & 235 & 1 \\
\hline Con centralidad urbana & 6 & 565.785 & 7,3 & 303 & 8 \\
\hline Comercial & 6 & 192.843 & 2,5 & 208 & 63 \\
\hline Industrial & 8 & 165.532 & 2,1 & 121 & 14 \\
\hline Dotacional & 7 & 93.235 & 1,2 & 166 & 14 \\
\hline Total & 108 & 7.746 .385 & 100,0 & 622 & 1 \\
\hline
\end{tabular}

Fuente: DANE, Secretaría Distrital de Planeación y Unidad Administrativa de Catastro Distrital; cálculos del autor.

E1 cuadro 2 muestra que en las 32 UPZ de urbanización incompleta vive la mayor parte de la población, con las densidades más altas: 622 hab./ha en Patio Bonito y Tunjuelito, una densidad un 342\% mayor que la de Manila, la metrópoli más densa según el Centre for Liveable Cities de Singapur (citado por Clark y Moir, 2015, 13), cuyo radio se extiende $200 \mathrm{~km}$ a partir de su centro, de apenas $38,6 \mathrm{~km}^{2}$, donde la densidad bruta llega a 428 hab./ha, similar a la de Minuto de Dios y Timiza, las más densas entre las zonas de desarrollo residencial consolidado (29), donde reside el 32,8\% de la población bogotana. 
Un $77,2 \%$ vive en zonas con la mayor presión poblacional, algunas de ellas existentes desde hace 55 años cuando estudios como el de Amato ya alertaban sobre las consecuencias socio-espaciales.

\section{ANÁLISIS POR TIPOS DE UPZ}

Las zonas de urbanización incompleta son producto de la necesidad y de la intervención reactiva del Estado (Abramo, 2011b), que determinan las decisiones de localización de las familias excluidas por la lógica mercantil y estatal de producción de espacio habitable. Cuando el uso de la tierra ocupada en forma espontánea es bajo, el Estado aplaza su intervención y da prioridad a asentamientos de mayor densidad donde la comunidad asume los costos de la regularización, como en La Flora (Hataya, 2010,362). En los barrios populares de densidades más altas la autoconstrucción y el desarrollo residencial progresivo inducen un crecimiento vertical (gráfica 2 y mapa 1 ).

Los barrios de las UPZ de uso residencial consolidado son más antiguos que los de urbanización incompleta y tienen mejores dotaciones. Muchos son asentamientos autoproducidos con baja movilidad residencial (Gilbert, 2001), lo que aumenta la densidad bruta sin mejorar su calidad. Las diferencias de calidad no son tan bajas como en el grupo anterior (gráfica 3 y mapa 2), aunque en algunos barrios de Arborizadora aún hay problemas urbanísticos y de dotación de bienes públicos. Las UPZ con densidad de mejor calidad, como Teusaquillo y La Alhambra, tienen barrios con relativa homogeneidad social, y a medida que esta se reduce aumenta la densidad bruta, pero la pendiente de su tendencia es la menor de todos los grupos. Son escasas las mezclas sociales como la de Pardo Rubio, y las capas medias predominan a medida que aumenta la densidad.

En uso residencial cualificado hay un número menor de UPZ y de barrios que en los dos anteriores, con calidades mayores asociadas a densidades brutas menores. Chicó Reservado y Alto, La Cabrera, E1 Nogal y Rosales, barrios "exclusivos" por el perfil empresarial de los jefes de hogar que viven allí, mientras que en Ciudad Salitre Occidental y Oriental se edifica una nueva centralidad que compite por localizaciones terciarias superiores con El Nogal, en particular por el auge de la construcción en Sauzalito. La cercanía al Centro Administrativo Nacional ha impulsado la construcción en altura de Rafael Núñez. La densidad bruta aumenta a costa de la calidad, de modo más notorio que en los grupos anteriores (gráfica 4 y mapa 3 ).

En las nueve UPZ de desarrollo se observan los mayores contrastes de localización y calidad (gráfica 5 y mapa 4). Las de mejor calidad 


\section{Gráfica 2}

Calidad de la densidad y densidad bruta UPZ de urbanización incompleta, 2014

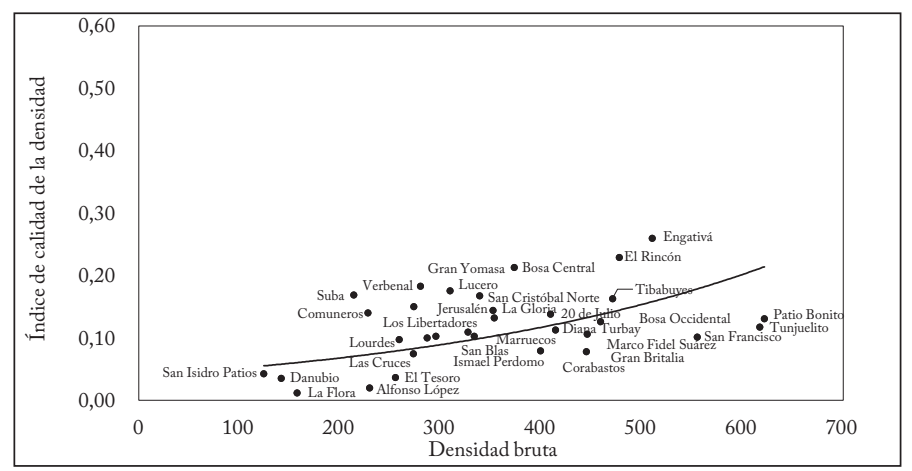

\section{Mapa 1}

ICD, UPZ de urbanización incompleta, 2014

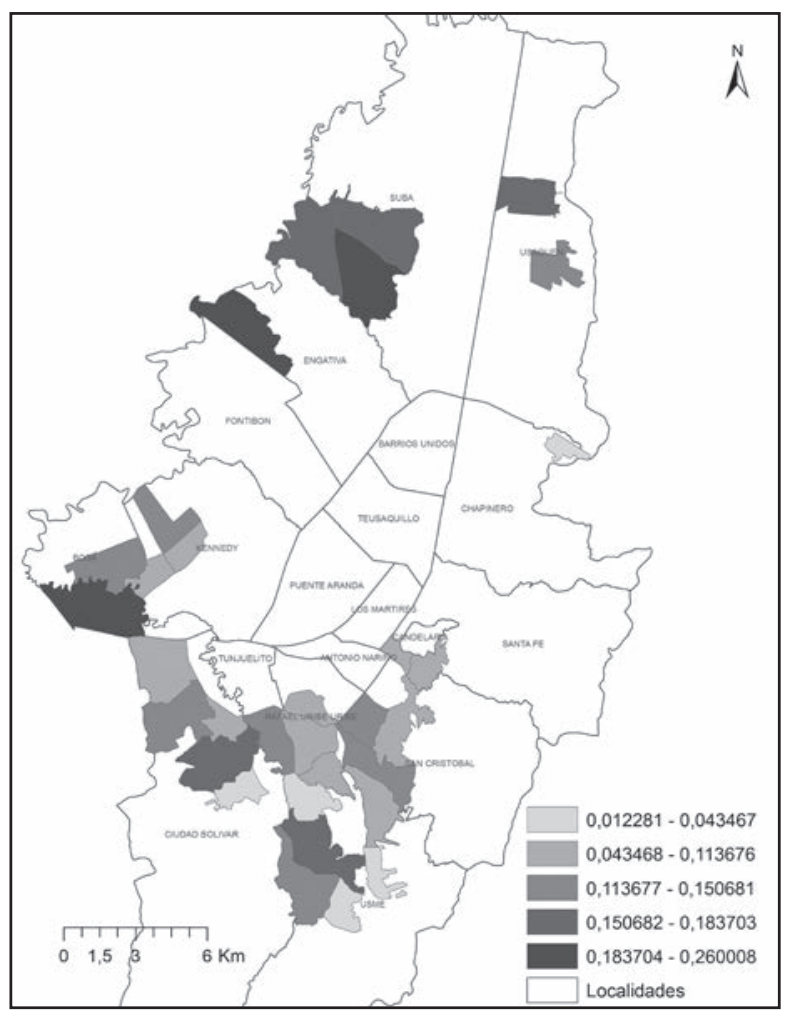

Fuente: DANE, Secretaría Distrital de Planeación y Unidad Administrativa de Catastro Distrital; cálculos del autor. 


\section{Gráfica 3}

Calidad de la densidad y densidad bruta UPZ de uso residencial consolidado, 2014

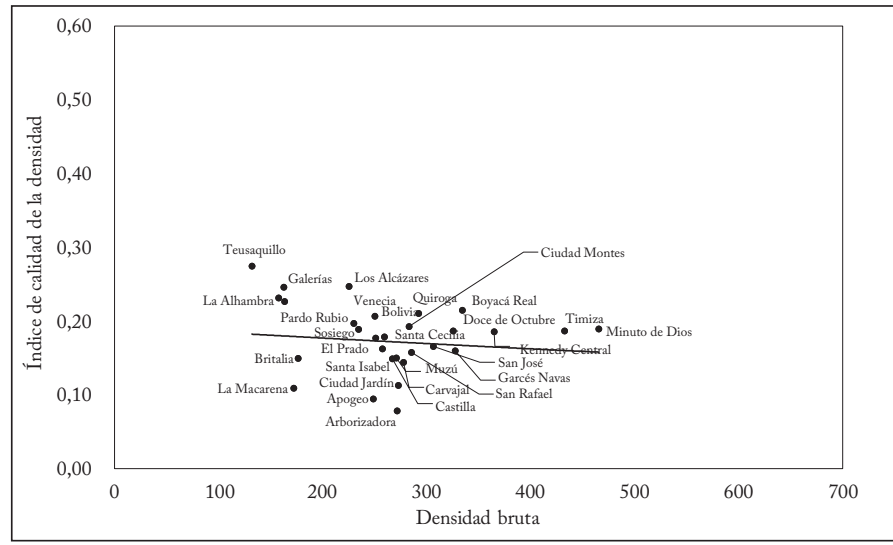

\section{Mapa 2}

ICD, UPZ de uso residencial consolidado, 2014

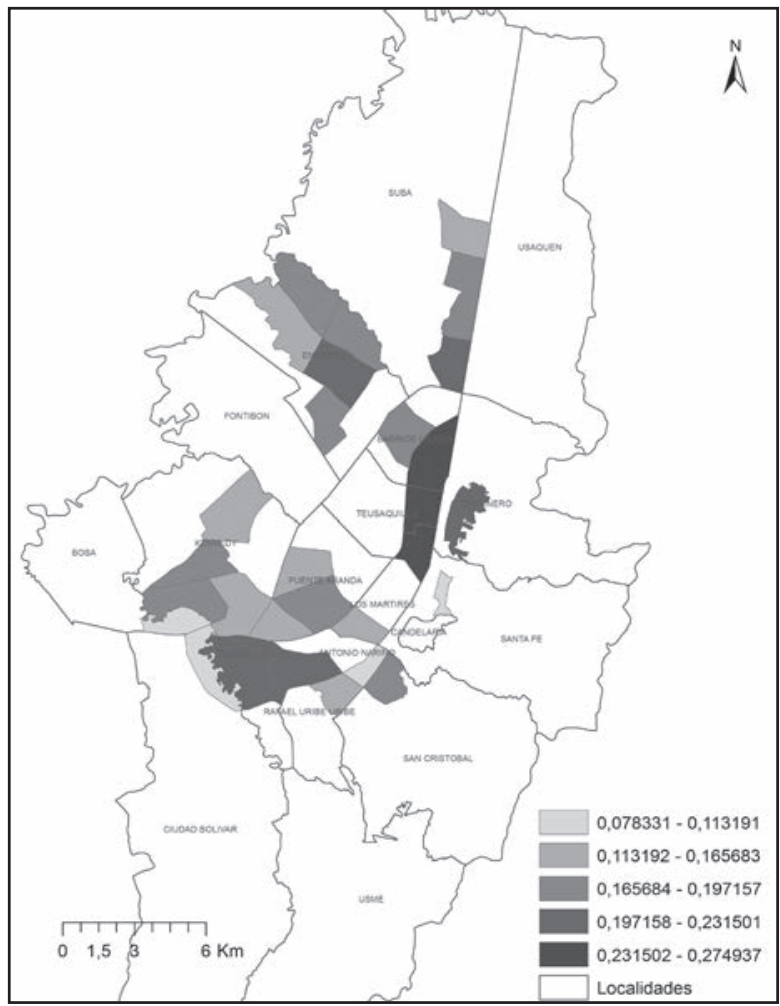

Fuente: DANE, Secretaría Distrital de Planeación y Unidad Administrativa de Catastro Distrital; cálculos del autor. 
están en el norte de la ciudad, cerca de los humedales de Guaymaral y Torca, asentadas en antiguas haciendas que acogen cementerios, clubes recreacionales y centros privados de educación básica y superior. Los vacíos urbanos propician el aumento de la densidad para uso residencial popular en UPZ del sur como E1 Mochuelo y Ciudad Usme, sin que se avizore una visible mejora de la calidad, como ocurrió con la fragmentación de E1 Porvenir.

El policentrismo urbano genera contrastes (gráfica 6 y mapa 5). Mientras que en Santa Bárbara y Usaquén se ha consolidado un comercio para capas de altos ingresos -en 1991 los zócalos del barrio San Patricio se transformaron en comercios de bienes importados-, en Las Ferias y el Restrepo hay un variado comercio popular diferente del comercio especializado de Fontibón y Américas asociado a las zonas industriales más cercanas. Es notorio el vacío espacial en las zonas de expansión popular donde la inexistencia de centralidad induce los mayores desplazamientos diarios de la residencia al lugar de trabajo y, por tanto, las dificultades de sus habitantes para reproducir su fuerza de trabajo y disfrutar el tiempo de ocio.

El epicentro de la terciarización de la economía es la localidad de Chapinero, a la que pertenecen Chicó Lago y Chapinero. En estas UPZ (gráfica 7 y mapa 6) vive la proporción más alta de jefes de hogar que son patrones o empleadores (16\%), más alta que en Teusaquillo (la segunda, con el 11\%). Allí la proporción de empleados domésticos es del 10\% y la de obreros o empleados del 59\%. Este perfil las distingue de otras, como Sagrado Corazón, que agrupa la mayoría de los barrios del Centro Internacional, y Las Nieves, con la que tiene vínculos perennes por su proximidad geográfica. En La Sabana hay zonas populares como San Victorino, y en Toberín el eje comercial se extiende por la Autopista Norte, con tramos especializados donde se aglomeran comercios de bienes afines.

Quienes viven cerca de las zonas industriales han formado vecindarios que en conjunto tienen las densidades brutas y calidades promedio más bajas de la ciudad (gráfica 8 y mapa 7). El flujo de carga en estas zonas es el más alto en días hábiles y no hábiles (Secretaría de Movilidad, 2015). Algunas de esas UPZ se formaron por su proximidad al Aeropuerto Eldorado y a las zonas francas; las demás, en el polígono industrial tradicional localizado alrededor del Parque Montevideo en la localidad de Puente Aranda. La contaminación, auditiva y del aire, generada por el transporte de carga terrestre y las aeronaves limita la demanda residencial en estas zonas, que tienden 
Gráfica 4

Calidad de la densidad y densidad bruta UPZ de uso residencial cualificado, 2014

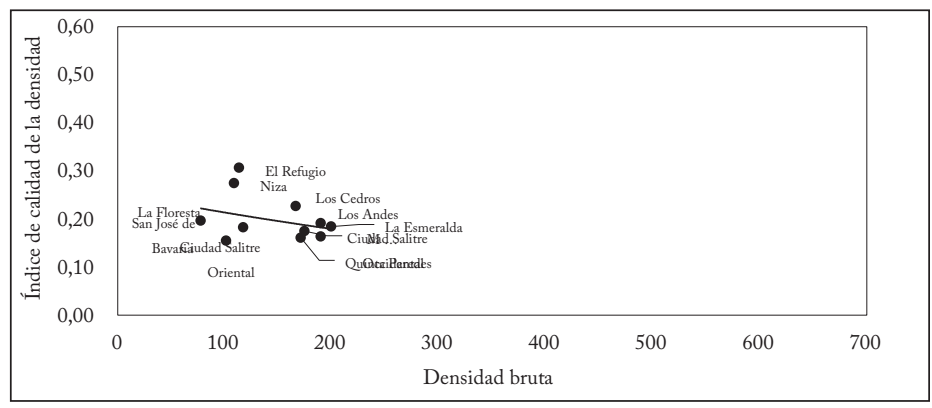

\section{Mapa 3}

ICD, UPZ de uso residencial cualificado, 2014

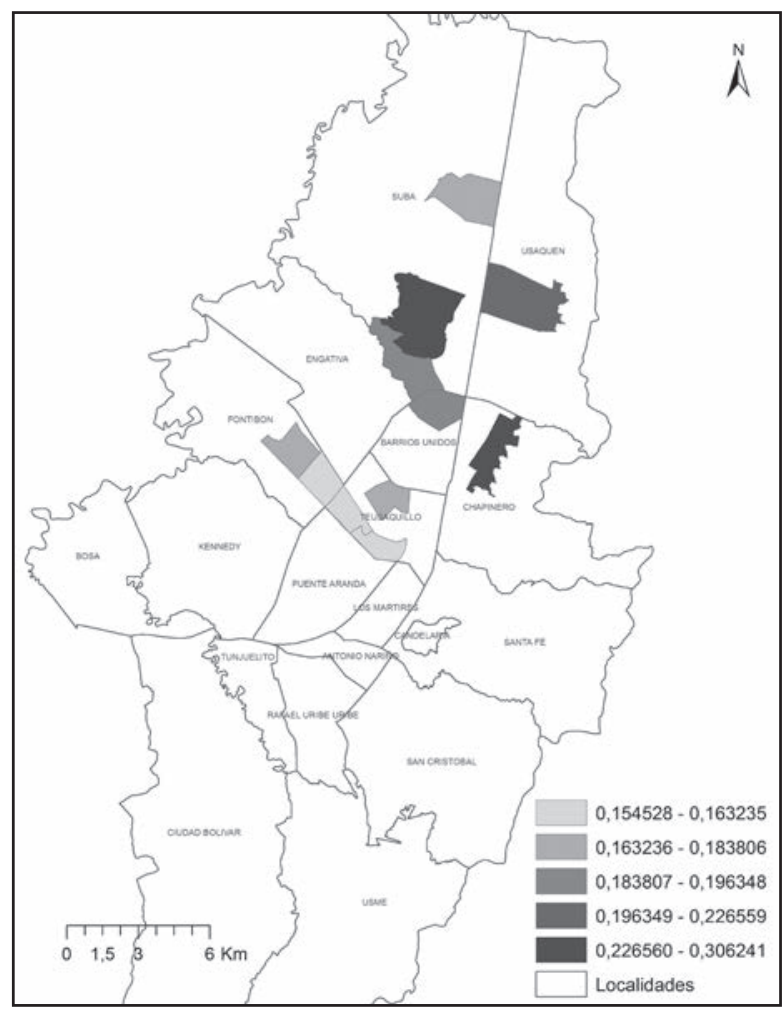

Fuente: DANE, Secretaría Distrital de Planeación y Unidad Administrativa de Catastro Distrital; cálculos del autor. 


\section{Gráfica 5}

Calidad de la densidad y densidad bruta UPZ de desarrollo, 2014

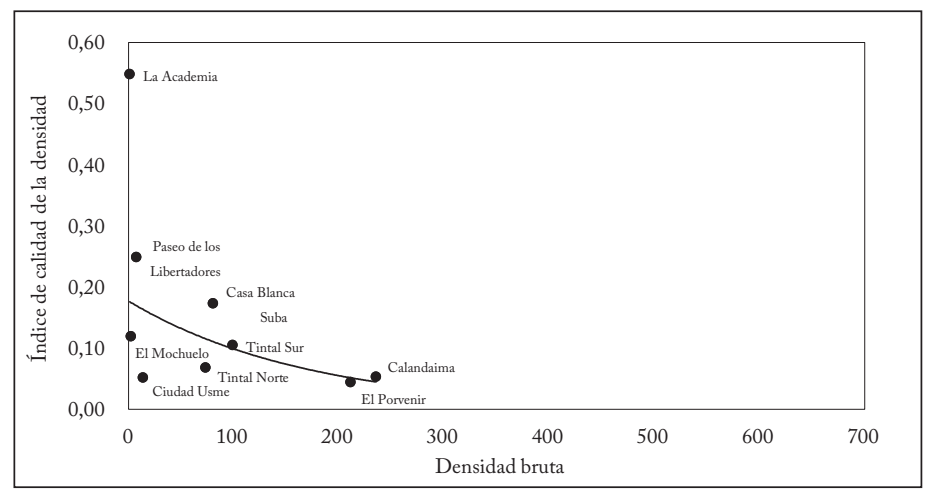

\section{Mapa 4}

ICD, UPZ de desarrollo, 2014

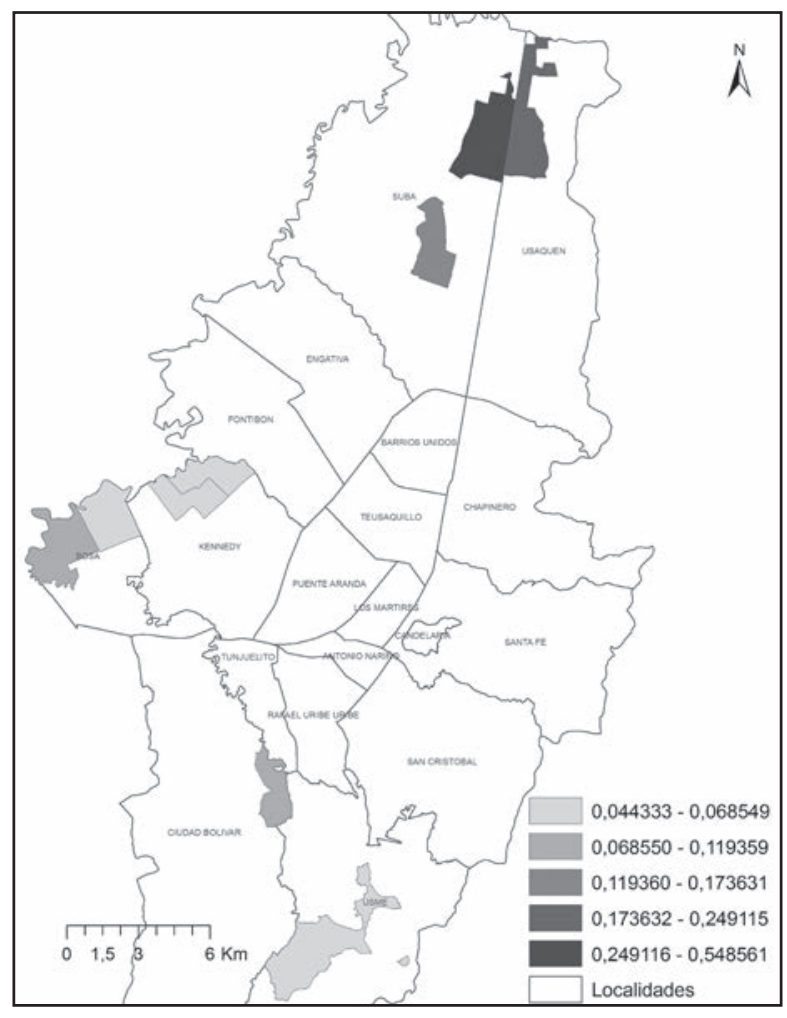

Fuente: DANE, Secretaría Distrital de Planeación y Unidad Administrativa de Catastro Distrital; cálculos del autor. 
Gráfica 6

Calidad de la densidad y densidad bruta

UPZ con centralidad urbana, 2014

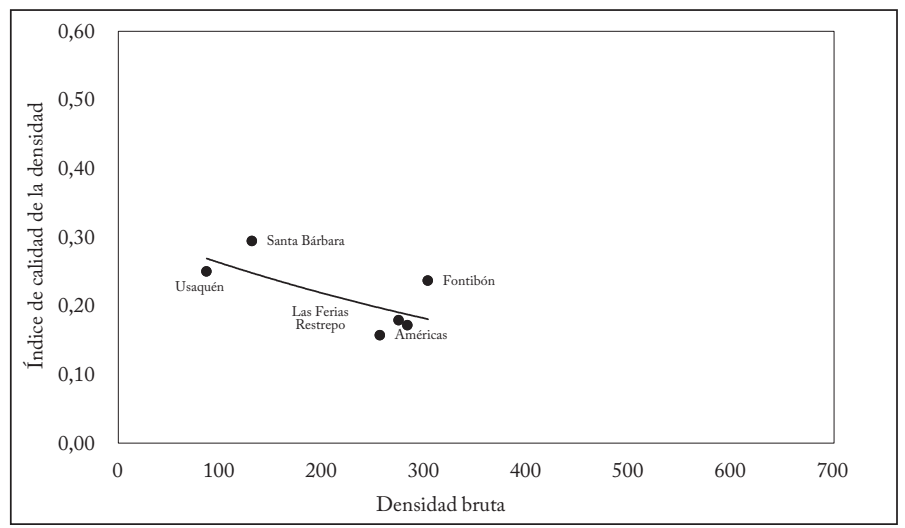

Mapa 5

ICD, UPZ con centralidad urbana, 2014

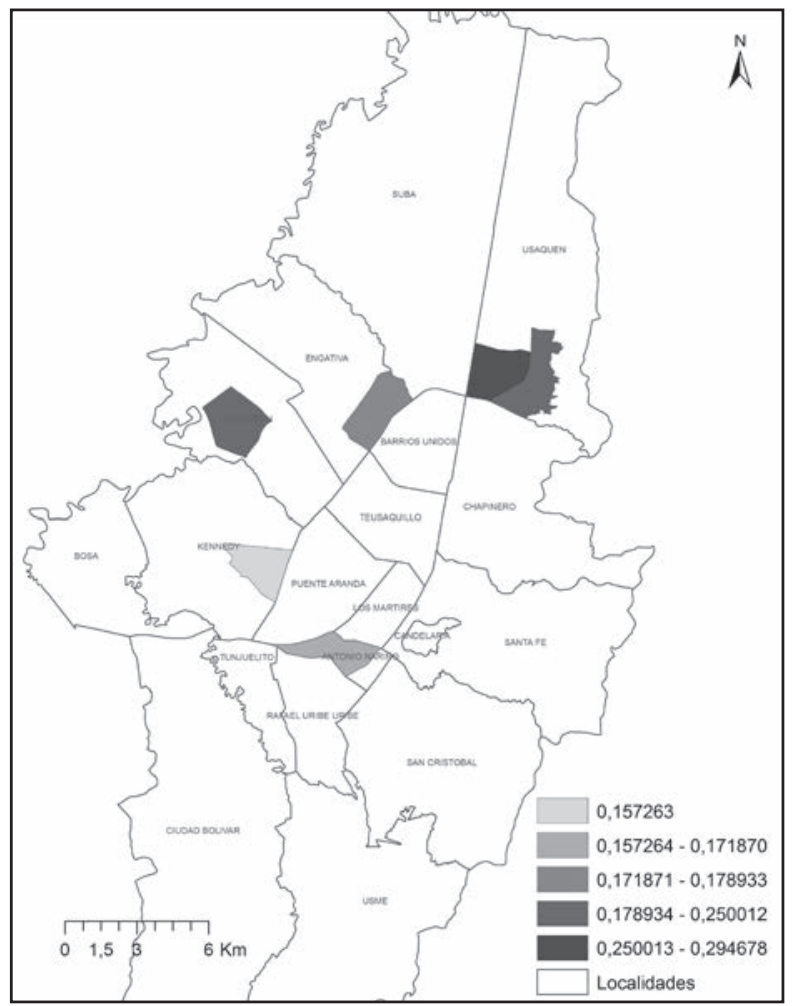

Fuente: DANE, Secretaría Distrital de Planeación y Unidad Administrativa de Catastro Distrital; cálculos del autor.

Revista de Economía Institucional, vol. i8, n.o 34, Primer semestre/2oi6, pp. 229-253 
Gráfica 7

Calidad de la densidad y densidad bruta UPZ comerciales, 2014

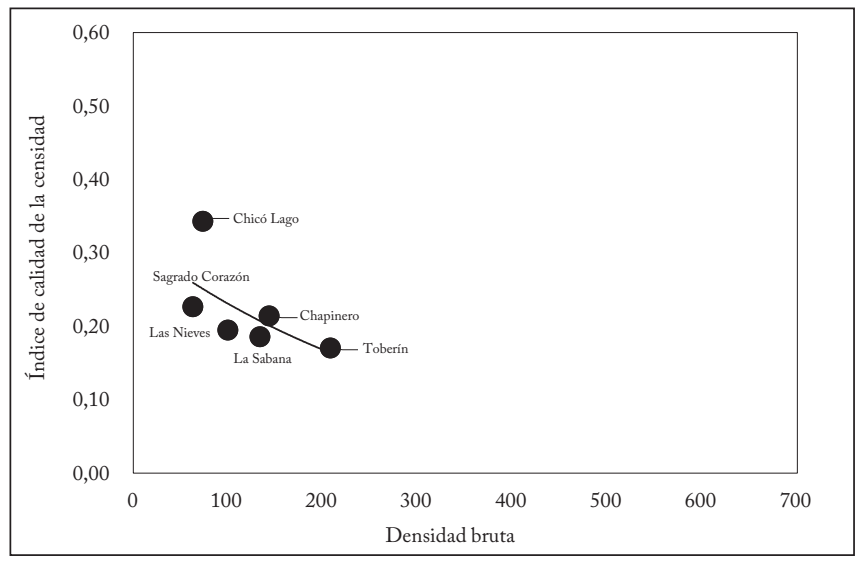

Mapa 6

ICD, UPZ comerciales, Bogotá 2014

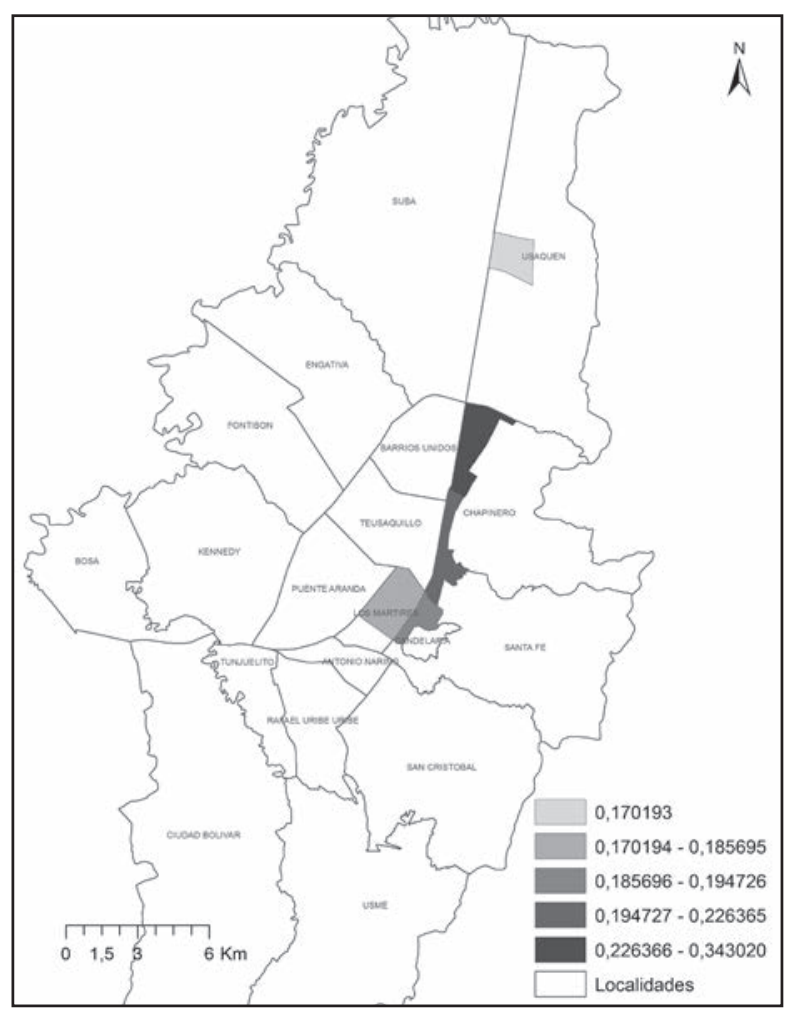

Fuente: DANE, Secretaría Distrital de Planeación y Unidad Administrativa de Catastro Distrital; cálculos del autor. 


\section{Gráfica 8}

Calidad de la densidad y densidad bruta UPZ industriales, 2014

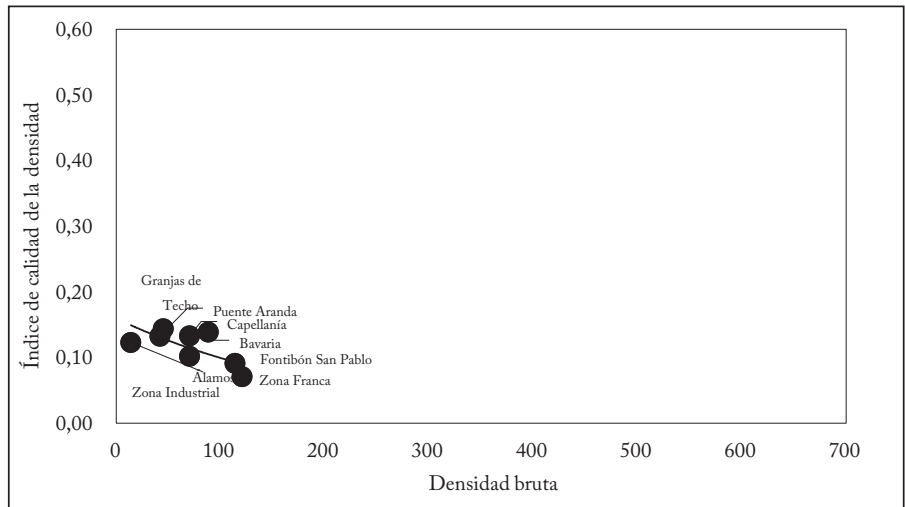

\section{Mapa 7}

ICD, UPZ industriales, 2014

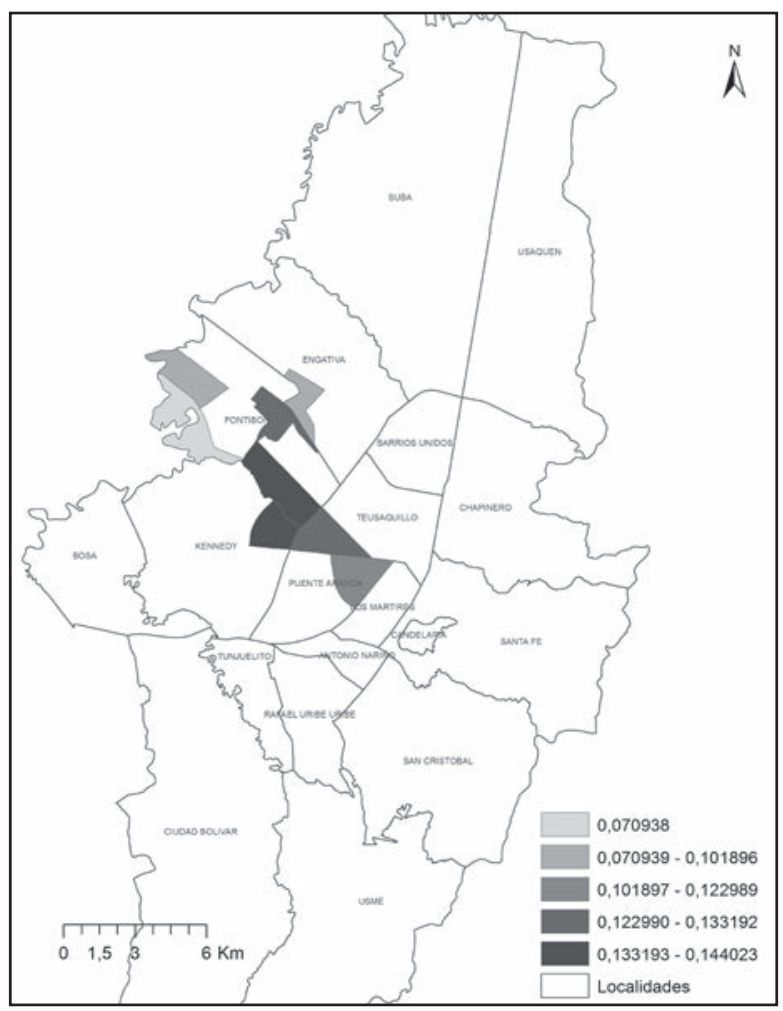

Fuente: DANE, Secretaría Distrital de Planeación y Unidad Administrativa de Catastro Distrital; cálculos del autor. 
a acoger familias obreras en vecindarios con poca dotación de bienes públicos, baja mezcla social y falta de espacios libres.

La mayoría de las UPZ dotacionales alojan los parques metropolitanos, escasos para una urbe con una densidad de población en aumento (gráfica 9 y mapa 8). Excepto La Candelaria que aloja actividades terciarias superiores: sedes del gobierno nacional y distrital, de órganos legislativos y de justicia, y universidades. Es el lugar central del centro tradicional de la ciudad y muestra mezclas sociales peculiares, matizadas por la presencia de extranjeros. Las Margaritas es un espacio libre cada día más estrecho para los habitantes del suroccidente y es la UPZ dotacional con la mayor presión poblacional, la mayor densidad bruta y la calidad más baja del grupo.

\section{VISIÓN DE CONJUNTO}

Por clasificación del suelo, Bogotá tiene dos grupos diferenciados de UPZ. El primero compuesto por vecindarios de predominio dotacional, comercial, con centralidad urbana y residencial cualificado, donde vive el 17,7\% de la población. En el segundo, donde reside la mayor parte de los habitantes, están las zonas residenciales de urbanización incompleta y consolidadas, las de desarrollo y de predominio industrial caracterizadas por su baja densidad (gráfica 10 y mapa 9). Las diferencias de densidad bruta que capta el índice del mapa 9a indican que las más altas se encuentran en los ejes de expansión residencial popular, hacia el sur, el nordeste y el noroeste, allí donde se observan los índices de calidad más bajos (mapa 9b).

Cabe destacar que las familias pudientes prefieren localizarse en zonas de baja densidad bruta, con ventajas dotacionales y próximas a aglomeraciones de actividades terciarias, donde hay una yuxtaposición de la densidad bruta y de la calidad. Pero hay zonas donde esta regla no se cumple debido a la regulación del uso del suelo y es pertinente el análisis particular a la luz de la clasificación del cuadro 2.

\section{REFLEXIONES FINALES}

La transformación social de América Latina tiene diferentes manifestaciones, una de ellas en el orden residencial, ligado a la intensidad de uso del suelo para vivienda. Como regla, se prefieren las bajas densidades a las más altas. Aunque en las urbes de América Latina, como Bogotá, existen vecindarios de baja densidad en una etapa previa a la regularización de la propiedad y a la legalización ante el Estado. Esta ambigüedad es reciente, a diferencia de lo que ocurría hace medio 


\section{Gráfica 9}

Calidad de la densidad y densidad bruta UPZ dotacionales, 2014

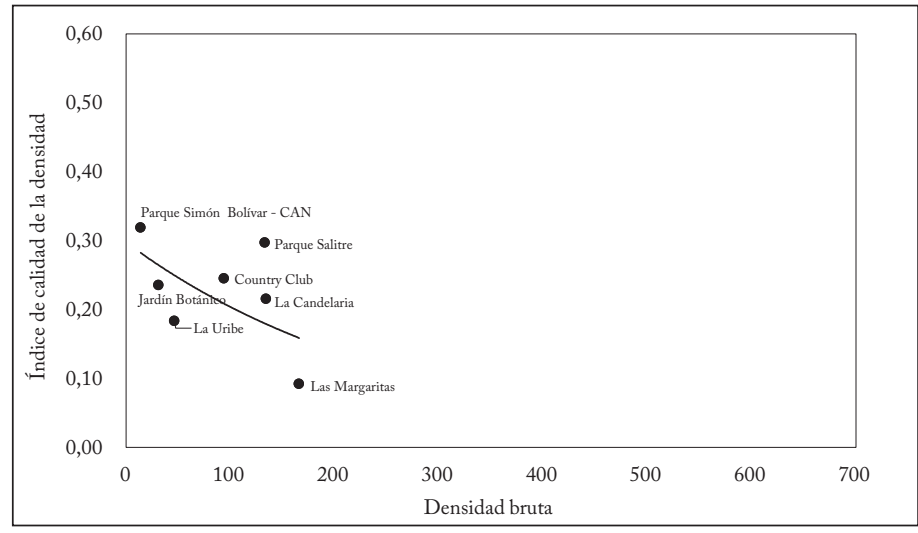

\section{Mapa 8}

ICD, UPZ dotacionales, 2014

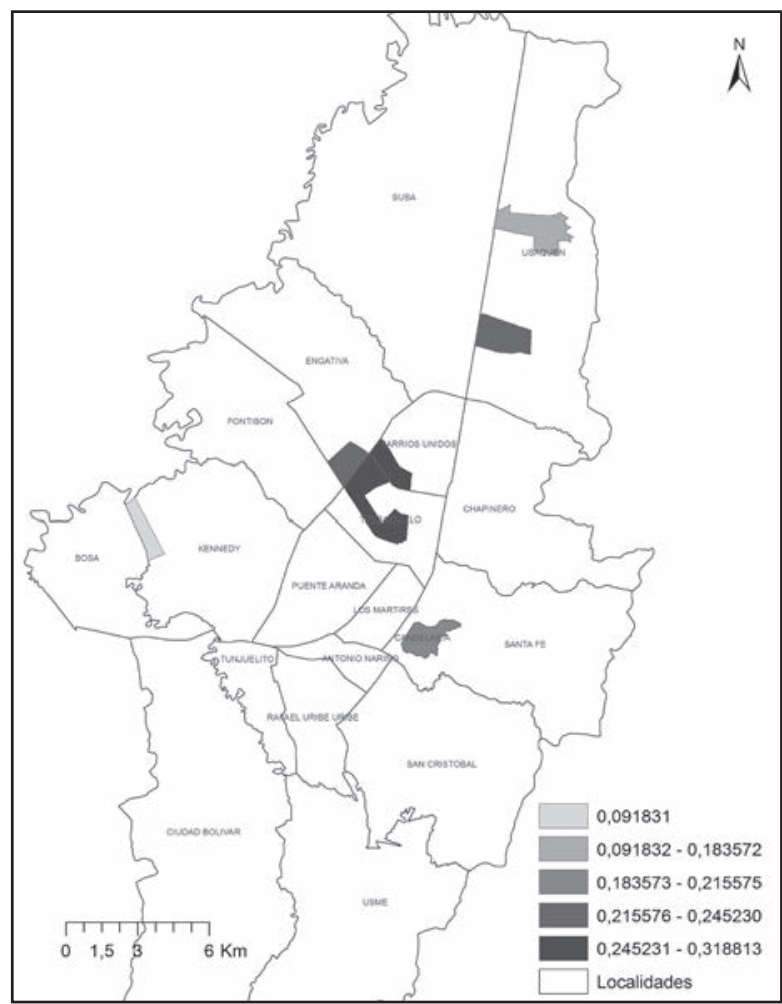

Fuente: DANE, Secretaría Distrital de Planeación y Unidad Administrativa de Catastro Distrital; elaboración del autor. 
Gráfica 10

Calidad de la densidad y densidad bruta según clasificación del suelo, 2014

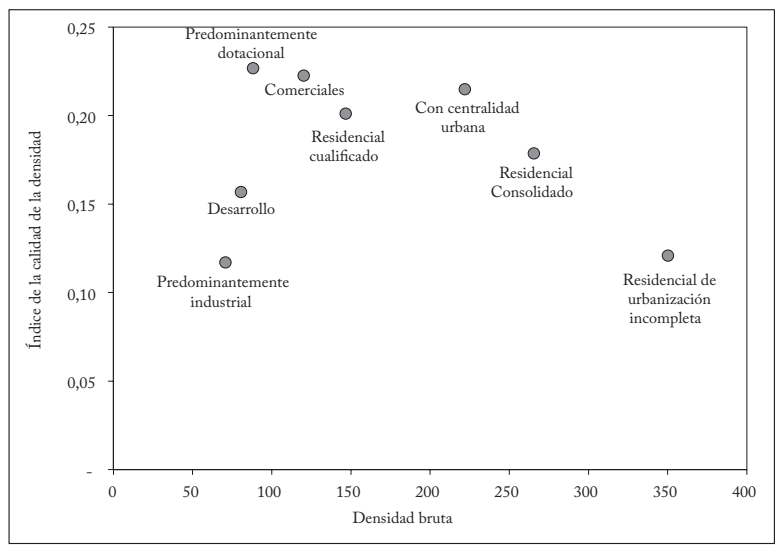

Fuente: DANE, Secretaría Distrital de Planeación y Unidad Administrativa de Catastro Distrital; elaboración del autor.

Mapa 9a

Índice de densidad bruta, 2014

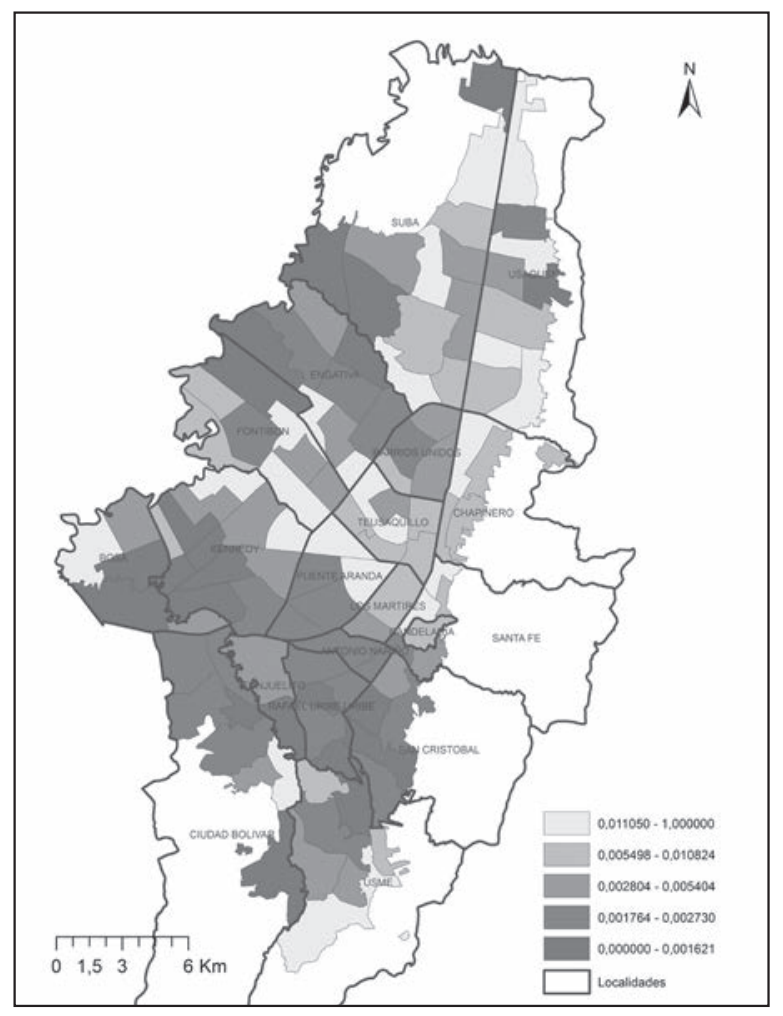

Revista de Economía Institucional, vol. i8, n.o 34, Primer semestre/2oi6, pp. $229^{-2} 53$ 
Mapa 9b

ICD, 2014

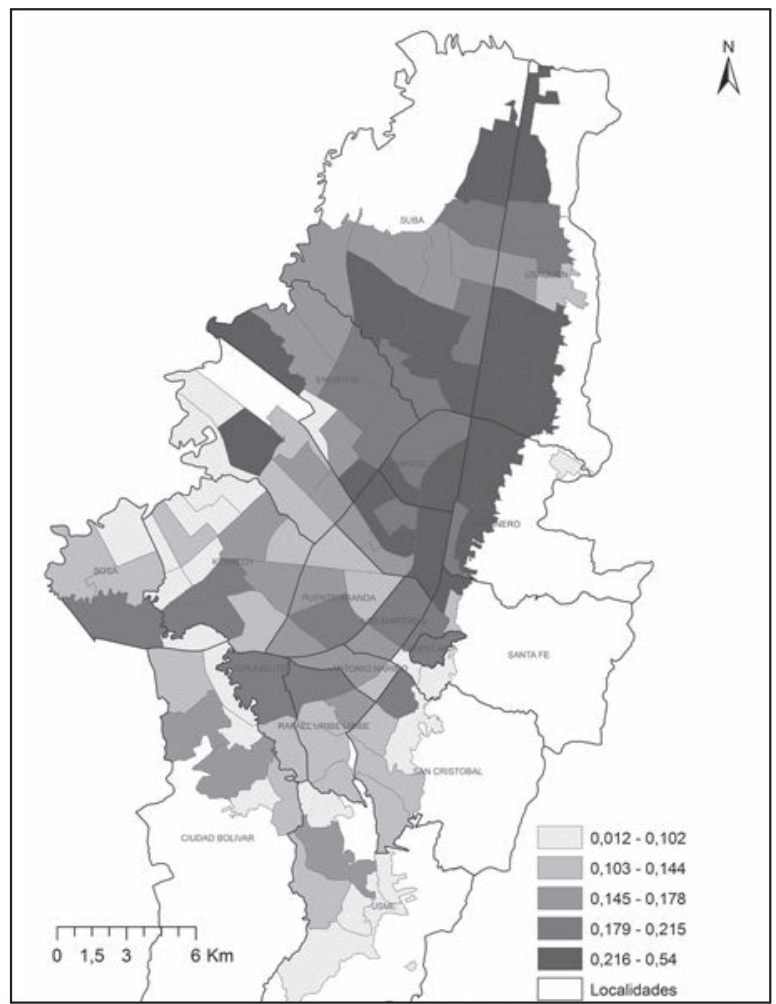

Fuente: DANE, Secretaría Distrital de Planeación y Unidad Administrativa de Catastro Distrital; elaboración propia.

siglo cuando el gradiente de densidad era muy nítido en la ciudad y en otras metrópolis del Tercer Mundo (Mohan, 1975).

Aunque la regulación urbana incide en la configuración del orden residencial por tipo de UPZ, buena parte del suelo desarrollado en Bogotá es producto de la intervención reactiva del Estado: de programas de regularización de la propiedad y de mejoramiento integral de los barrios. La informalidad urbana se produce y se reproduce con altas densidades para acoger familias pobres cuya baja capacidad de pago no les permite satisfacer su necesidad de vivienda a través de mecanismos formales. Las diferencias de calidad de la densidad son también diferencias de calidad de vida. De allí la importancia social y política de la regulación y de la política urbana para modificar el orden social excluyente pues, a diferencia de una siempre aplazada redistribución del ingreso, el acceso a viviendas de buena calidad tiene gran potencial 
para lograr la justicia espacial. La tarea es enorme pues solo el 17,7\% de los habitantes de Bogotá viven con una calidad aceptable.

Varios procesos en curso agudizan la segregación socio-espacial y afectan la densidad bruta y su calidad. Por un lado, la espontaneidad de la ocupación propia de los vecindarios informales es inseparable del desarrollo progresivo de la vivienda que provoca aumentos de la densidad bruta, mientras que las viviendas en serie y la construcción vertical ocupan velozmente las pocas áreas edificables. Por su parte, la gentrificación es impulsada por instrumentos de renovación y regeneración urbana, como la construcción en altura de viviendas de poca área en el centro tradicional para hogares unipersonales, que hoy representan un $15 \%$ del total. Este factor demográfico reduce la densidad poblacional y aumenta la densidad constructiva en el centro, fenómeno yuxtapuesto al que ocurre en los ejes de expansión popular donde viven las familias de mayor tamaño; por ello, la densidad de población aumenta secularmente. La gestión socio-territorial de la transición demográfica es así otro factor de segregación residencial.

\section{REFERENCIAS BIBLIOGRÁFICAS}

1. Abramo, P. La ciudad caleidoscópica, coordinación espacial y convención urbana: una perspectiva heterodoxa para la economía urbana, Bogotá, Universidad Externado de Colombia, 2011a.

2. Abramo, P. La producción de las ciudades latinoamericanas: mercado inmobiliario y estructura urbana, serie Textos Urbanos 9, Quito, OLACCHI, 2011b.

3. Acioly Jr., C. y F. Davidson. Um instrumento de planejamento e gestão urbana, Río de Janeiro, Institute for Housing and Urban Development Studies, 1998.

4. Acosta, J.; A. Maluendas y G. Rivas. "Indicadores socioeconómicos y su relación con la estratificación y la información catastral”, C. E. Sepúlveda et al., eds., Los límites de la estratificación: en busca de alternativas, Bogotá, Universidad del Rosario-Alcaldía Mayor de Bogotá, 2014.

5. Alfonso, Ó. "Aportes a una teoría de la estructuración residencial urbana", Revista de Economía Institucional 9, 17, 2007, pp. 241-277.

6. Alfonso, Ó. "Economía institucional de la ocupación del suelo en la región metropolitana de Bogotá", documentos de trabajo 28, Bogotá, Universidad Externado de Colombia, 2009.

7. Alfonso, Ó. "Urbanismo ordenado pero no pasteurizado: origen del corporatismo y orden socio-espacial en Bogotá hacia 1910", Ó. Alfonso et al., eds., El centro tradicional de Bogotá: valor de uso popular y patrimonio arquitectónico de la ciudad, Bogotá, Universidad Externado de Colombia, 2012. 
8. Alfonso, Ó. y C. Alonso. Análisis de la convergencia regional desde el espacio geográfico y el gasto de los hogares: una medición para Bogotá y su zona metropolitana, colección Integración Regional 22, Bogotá, Secretaría Distrital de Planeación, 2015.

9. Clark, G. y E. Moir. Density: Drivers, dividends and debates, Londres, Urban Land Institute, 2015.

10. Eibenschutz H., R. y P. Benlliure. Mercado formal e informal del suelo: análisis de ocho ciudades, México, DF, Porrúa-UAM, 2009.

11. Fouchier, V. "The density concept and its social implications", V. Fouchier et al., eds., High urban densities. A solution for our cities?, Hong Kong, Consulate General of France in Hong Kong-French Institute of Town Planning, 1994.

12. Fujita, M. Urban economic theory: Land use and city size, Nueva York, Cambridge University Press, 1989.

13. Gilbert, A. “¿Una casa es para siempre? Movilidad residencial y propiedad de la vivienda en los asentamientos autoproducidos”, $T e-$ rritorios, 6, 2001, pp. 51-73.

14. Hataya, N. La ilusión de la participación comunitaria: lucha y negociación en los barrios irregulares de Bogotá 1992-2003, Bogotá, Universidad Externado de Colombia, 2010.

15. Jaramillo, S. Hacia una teoría de la renta del suelo urbano, Bogotá, Uniandes, 2009.

16. Le Roux, G. “(Re)connaître le stade de peuplement actuel des grandes villes latino-américaines: diversification des parcours et des échelles du changement urbain à Bogotá”, tesis de doctorado en Geografía, Universidad de Poitiers, 2015.

17. Merlin, P. "Housing theories, models of urban development, densities and transportation", V. Fouchier et al., eds., High urban densities. A solution for our cities?, Hong Kong, Consulate General of France in Hong Kong-French Institute of Town Planning, 1994.

18. Mohan, R. "Urban land policy, income distribution and the urban poor”, discussion paper 51, New Jersey, Princeton University, 1975.

19. Rallet, A. "Economia da proximidade: em direção a um balanço", Cadernos IPPUR 16, 2, 2002.

20. Richardson, H. W. Economía regional y urbana, Madrid, Alianza, 1986.

21. Sáenz A., H. "A reciprocidade como marco institucional dos contratos de locação residencial: $O$ casso de Patio Bonito I, um bairro popular na Bogotá, Colômbia”, tese de doutorado, IPPUR/Universidade Federal do Rio de Janeiro, 2015.

22. Secretaría de Movilidad. "Actualización y ajuste de la matriz origendestino de transporte de carga de la ciudad de Bogotá D.C.”, Alcaldía Mayor de Bogotá, 2015.

23. Uribe M., C. "Estratificación social en Bogotá: de la política pública a la dinámica de la segregación social”, Universitas Humanística 65, 2008, pp. 139-171.

24. Wingo, L. Transporte y suelo urbano, Barcelona, Oikos, 1972.

25. Wolsink, M. "Wind power and the NIMBY-myth: Institutional capacity and the limited significance of public support", Journal of Renewable Energy 21, 1, 2000, pp. 49-64. 